IUCrJ

ISSN 2052-2525

BIOLOGY|MEDICINE

Received 22 February 2019

Accepted 6 June 2019

Edited by J. L. Smith, University of Michigan, USA

Keywords: ultralow-temperature X-ray crystallography; XANES; heme protein; neuroglobin; oxygen binding; cryo-trapping; crystal microspectroscopy; neuroprotection; structural biology; CO photolysis; soak-andfreeze pressurization; structure determination; protein structure.

PDB references: Ngb under 50 bar $\mathrm{O}_{2}$ pressure, $5 \mathrm{mjc}$; $\mathrm{Ngb}$ under 80 bar $\mathrm{O}_{2}$ pressure, $5 \mathrm{mjd}$; NgbCO without illumination, 6i3t; NgbCO under illumination, $6 \mathbf{i} 40$

Supporting information: this article has supporting information at www.iucrj.org

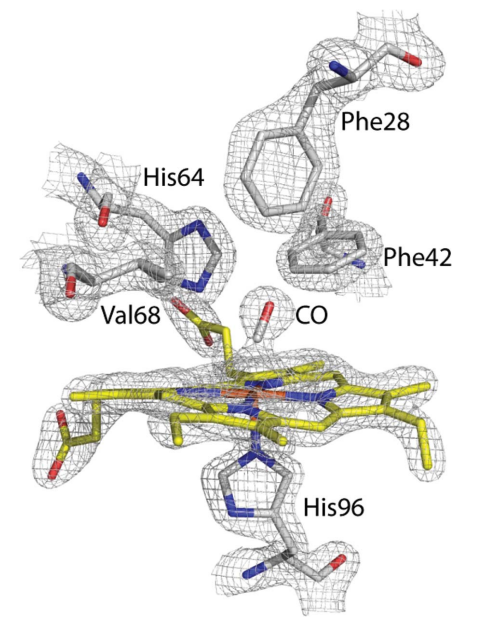

OPEN $\odot$ ACCESS

\section{Ligand pathways in neuroglobin revealed by low-temperature photodissociation and docking experiments}

\author{
Chiara Ardiccioni, ${ }^{a}$ Alessandro Arcovito, ${ }^{\text {b,c }}$ Stefano Della Longa, ${ }^{\mathrm{d}}$ Peter van der \\ Linden, ${ }^{\text {e,f }}$ Dominique Bourgeois, ${ }^{\mathrm{g}}$ Martin Weik, ${ }^{\mathrm{g}}$ Linda Celeste Montemiglio, ${ }^{\mathrm{h}, \mathrm{i}, \mathrm{j}}$ \\ Carmelinda Savino, ${ }^{i}$ Giovanna Avella, ${ }^{\text {h,k }}$ Cécile Exertier, ${ }^{\text {h }}$ Philippe Carpentier, ${ }^{\mathrm{e}, \mathrm{l}}$ \\ Thierry Prangé, ${ }^{\mathrm{m}}$ Maurizio Brunori, ${ }^{\mathrm{h}}$ Nathalie Colloc' $\mathrm{h}^{\mathrm{n}}$ and Beatrice Vallone $\mathrm{e}^{\mathrm{h}, \mathrm{i}, \mathrm{j} *}$
}

\begin{abstract}
${ }^{a}$ Department of Life and Environmental Sciences, New York-Marche Structural Biology Center (NY-MaSBiC), Polytechnic University of Marche, Ancona, Italy, ${ }^{\mathbf{b}}$ Istituto di Biochimica e Biochimica Clinica, Universitá Cattolica del Sacro Cuore, Largo Francesco Vito 1, 00168 Rome, Italy, ${ }^{{ }^{c}}$ Fondazione Policlinico Universitario Agostino Gemelli-IRCCS, Largo Francesco Vito 1, 00168 Rome, Italy, 'Department of Life, Health and Environmental Sciences, University of L'Aquila, 67100 L'Aquila, Italy, ${ }^{\mathbf{e} E u r o p e a n}$ Synchrotron Radiation Facility (ESRF), 38043 Grenoble, France, ${ }^{\mathbf{f}}$ Partnership for Soft Condensed Matter (PSCM), 38043 Grenoble, France, ${ }^{\mathrm{g}}$ Université Grenoble Alpes, CEA, CNRS, IBS, 38000 Grenoble, France, 'Department of Biochemical Sciences 'A. Rossi Fanelli', University of Rome Sapienza, Piazzale Aldo Moro 5, 00185 Rome, Italy, 'Institute of Molecular Biology and Pathology, National Research Council, Piazzale Aldo Moro 5, 00185 Rome, Italy, 'Istituto Pasteur-Fondazione Cenci Bolognetti, Department of Biochemical Sciences 'A. Rossi Fanelli',

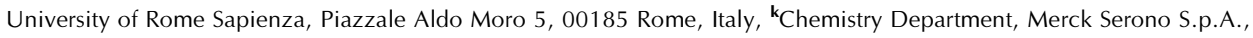
Via Casilina 125, 00176 Rome, Italy, 'CEA/DRF/BIG/CBM/BioCat LCBM CNRS UMR 5249, Université Grenoble Alpes, 38000 Grenoble, France, ${ }^{\mathbf{m}}$ CiTeCoM UMR 8038 CNRS, Université Paris Descartes, Paris, France, and " ISTCT UMR 6030 CNRS Université de Caen Normandie CEA, CERVOxy Team, Centre Cyceron, Caen, France. *Correspondence e-mail: beatrice.vallone@uniroma1.it
\end{abstract}

A combined biophysical approach was applied to map gas-docking sites within murine neuroglobin $(\mathrm{Ngb})$, revealing snapshots of events that might govern activity and dynamics in this unique hexacoordinate globin, which is most likely to be involved in gas-sensing in the central nervous system and for which a precise mechanism of action remains to be elucidated. The application of UVvisible microspectroscopy in crystallo, solution X-ray absorption near-edge spectroscopy and X-ray diffraction experiments at $15-40 \mathrm{~K}$ provided the structural characterization of an $\mathrm{Ngb}$ photolytic intermediate by cryo-trapping and allowed direct observation of the relocation of carbon monoxide within the distal heme pocket after photodissociation. Moreover, X-ray diffraction at $100 \mathrm{~K}$ under a high pressure of dioxygen, a physiological ligand of Ngb, unravelled the existence of a storage site for $\mathrm{O}_{2}$ in $\mathrm{Ngb}$ which coincides with Xe-III, a previously described docking site for xenon or krypton. Notably, no other secondary sites were observed under our experimental conditions.

\section{Introduction}

Neuroglobin $(\mathrm{Ngb})$ is a member of the globin protein family that is expressed in the brain $(\sim 1 \mu M)$ and the retina $(\sim 100 \mu M)$ of vertebrates (Burmester et al., 2000). It is involved in the protection of the nervous tissue from ischemic damage via a still-elusive biochemical mechanism. $\mathrm{Ngb}$ is a highly conserved protein, with a mutation rate about threefold slower than those of myoglobin $(\mathrm{Mb})$ and hemoglobin $(\mathrm{Hb})$ (Burmester \& Hankeln, 2004), suggesting a mechanism of action that requires stringent structural constraints. Several hypotheses about the functions of $\mathrm{Ngb}$ have been put forward over and above $\mathrm{O}_{2}$ binding and transport: (i) it may act as a cytochrome $c$ reductase, (ii) it may be involved in a signal transduction pathway by controlling the dissociation of GDP from the $G$ protein $\alpha$ subunit and (iii) it may scavenge damaging oxygen or nitrogen radicals, for example under 
normoxia it may detoxify a harmful excess of nitric oxide (NO) to nitrate $\left(\mathrm{NO}_{3}^{-}\right)$, while under hypoxia it may produce NO from nitrite $\left(\mathrm{NO}_{2}^{-}\right)$for blood-pressure control (Jin et al., 2008; Tiso et al., 2011; Ascenzi et al., 2014).

In spite of its low similarity in sequence (less than 25\%) relative to $\mathrm{Mb}$ and $\mathrm{Hb}$ (Burmester et al., 2000), Ngb displays the typical globin fold (a $3 / 3 \alpha$-helical structure) and retains the key structural determinants of globins: the proximal His(F8)96 that coordinates the heme iron and the distal His(E7)64 that controls ligand affinity and selectivity at the sixth iron-coordination position (Dewilde et al., 2001; Guimarães et al., 2014; Pesce et al., 2004; Vallone, Nienhaus, Brunori et al., 2004). Notably, Ngb is also a hexacoordinate protein in the 'deoxy' ferrous form, with the rate-limiting step for ligand binding being the spontaneous breakage of the distal His(E7)64-heme bond.

It has been shown by crystallography (Vallone, Nienhaus, Matthes et al., 2004) that a conformational transition involving a sliding of the heme has to take place in order to create the space to accommodate an external ligand, which is a unique mechanism for ligand-affinity modulation in the globin family. This heme sliding counterbalances the presence of internal coordination, leading to a different protein conformation and promoting the accessibility of the heme pocket to $\mathrm{O}_{2}$ and other external ligands (Avella et al., 2014; Exertier et al., 2019).

$\mathrm{Ngb}$ is endowed with a large hydrophobic cavity $\left(300 \AA^{3}\right)$ and a substantial 'tunnel' displaying two branches, which extend around the heme and connect the distal and the proximal sides of the heme pocket, together with an alternate tunnel (Fig. 1; Colloc'h et al., 2008; Vallone, Nienhaus, Brunori et al., 2004). The heme sliding coupled to ligand binding affects

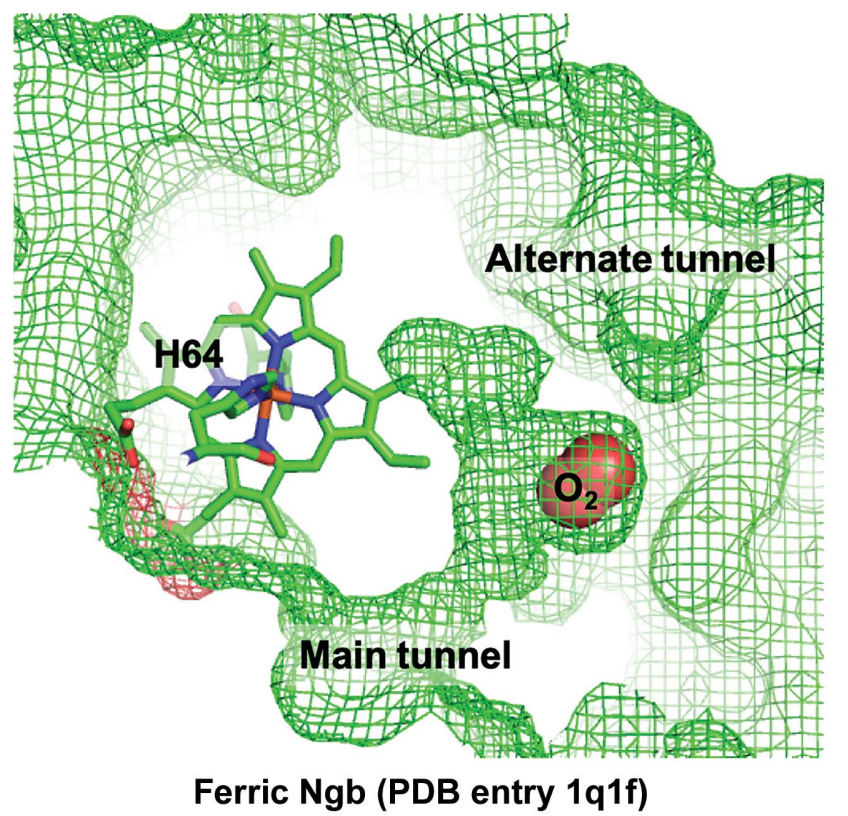

(a) the topology of the cavity, drastically reducing the proximal branch and enlarging the distal branch. In analogy to the internal packing defects detected in $\mathrm{Mb}$, this tunnel implies an offset in terms of thermodynamic stability. Since cavities play a functional role in $\mathrm{Mb}$ by regulating the dynamics of ligand binding (Brunori \& Gibson, 2001; Schlichting \& Chu, 2000), it has been proposed that the $\mathrm{Ngb}$ tunnel, which represents an amplification of the set of $\mathrm{Mb}$ internal cavities, may play a similar role (Moschetti et al., 2009; Colloc'h, Carpentier et al., 2017). This hypothesis was supported by molecular-dynamics (MD) simulations, showing the similarity between the cavity system in Ngb and the xenon sites in Mb (Anselmi et al., 2007), since during MD trajectories they both host ligands and constitute a preferential pathway for migration within the protein. High hydrostatic pressure also reinforces this hypothesis, showing that Ngb would hinge around a mechanical nucleus of five hydrophobic residues (Val68, Ile72, Val109, Leu113 and Tyr137) lining the cavity just behind the heme (Colloc'h, Sacquin-Mora et al., 2017). Mutation studies have indeed highlighted the possibility that these residues could be involved in ligand migration (Astudillo et al., 2012; Tejero et al., 2015).

In globins, the network of cavities has been investigated extensively to characterize their role and dynamics, and it was shown that xenon docks into these apolar niches (de Sanctis et al., 2004; Milani et al., 2004; Moschetti et al., 2009; Savino et al., 2009; Tilton et al., 1994; Abraini et al., 2014). Moreover, direct crystallographic detection of $\mathrm{CO}$ in the protein matrix was reported in $\mathrm{Hb}$ and $\mathrm{Mb}$ by cryotrapping using helium cryostats under photodissociating conditions (Adachi et al., 2003; Brunori, 2000; Schlichting et al., 1994; Schmidt et al., 2005).

Figure 1

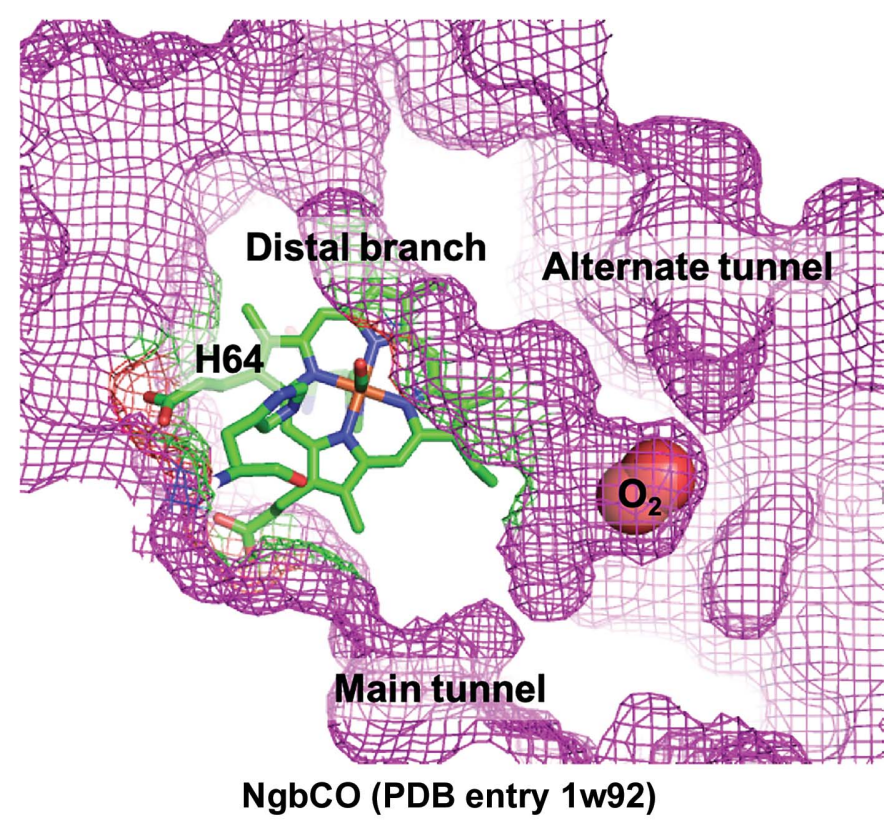

(b)

Large hydrophobic cavity and $\mathrm{O}_{2}$-docking sites in $\mathrm{Ngb}$. The determination of neuroglobin structures in 2004 unravelled the existence of a large hydrophobic internal cavity in which the heme is accommodated, along with the main 'tunnel' and an alternate tunnel connecting this cavity to the bulk. The internal cavity and tunnels are shown in green $(a)$ for hexacoordinate ferric Ngb (PDB entry 1q1f; Vallone, Nienhaus, Brunori et al., 2004) and in magenta $(b)$ for CO-bound Ngb (PDB entry 1w92; Vallone, Nienhaus, Matthes et al., 2004), in which the location of $\mathrm{O}_{2}$ has been modelled within the cavity. 
Time-resolved Laue crystallography at synchrotrons (Bourgeois et al., 2006) and XFELs (Barends et al., 2015) unveiled the subtle protein dynamics involved in ligand migration of photodissociated $\mathrm{CO}$ into $\mathrm{Mb}$ cavities on fast and ultrafast timescales, respectively. In solution, time-resolved spectroscopy detected the presence of ligand-docking intermediates in Mb (Lim et al., 1997; Nienhaus et al., 1994), and in silico MD simulations analysed the presence of transient cavities and gaseous ligand-migration pathways (Amadei \& Vallone, 1996; Bossa et al., 2005; Elber \& Karplus, 1987). The general picture that emerged from several experimental and theoretical approaches on globins is that cavities modulate ligand kinetics and therefore protein reactivity.

In the case of $\mathrm{Ngb}$, the presence of a heme iron-bound distal His(E7)64 and of the exogenous ligand-linked 'heme sliding' structural transition demand ad hoc investigation to evaluate the internal structural dynamics and the migration pathways of small gaseous ligands $\left(\mathrm{CO}\right.$ and $\left.\mathrm{O}_{2}\right)$. In this work, the problem of the function of internal cavities is approached using several concurrent methodologies, i.e. UV-visible singlecrystal microspectrophotometry to investigate the in crystallo optical spectra of NgbCO, X-ray diffraction (XRD) and X-ray absorption near-edge structure spectroscopy (XANES) at low temperatures to determine the three-dimensional structure of $\mathrm{NgbCO}$ and of the photoproduct $\mathrm{Ngb} * \mathrm{CO}$ (obtained either by steady visible illumination in the crystal or by long X-ray exposure in solution). Moreover, the three-dimensional structure of ferric $\mathrm{Ngb}$ (not competent for $\mathrm{CO} / \mathrm{O}_{2}$ binding) under increasing $\mathrm{O}_{2}$ pressure was investigated in order to find out whether internal cavities in Ngb may act as storage niches for this small gaseous reactant as observed when using Xe or $\mathrm{Kr}$ as probes (Colloc'h et al., 2008; Duff et al., 2004; Lafumat et al., 2016).

\section{Experimental procedures}

\subsection{Protein purification and crystallization}

The expression, purification and crystallization of recombinant murine ferric Ngb (with Ser55 and Ser120 mutated to Cys) were carried out as described by Arcovito et al. (2007).

Crystals of the NgbCO derivative were obtained as reported previously (Vallone, Nienhaus, Matthes et al., 2004) by treating ferric $\mathrm{Ngb}$ crystals with sodium dithionite to obtain the ferrous form competent for $\mathrm{CO}$ binding and then soaking them in CO-saturated mother liquor. Crystals that undergo this treatment have to be promptly cooled as they tend to dissolve upon prolonged exposure to CO.

\subsection{In crystallo UV-visible microspectroscopy at 15 and $30 \mathrm{~K}$}

Single NgbCO crystals were analysed by UV-visible microspectroscopy. The UV-visible microspectrophotometer includes a detector that can perform both absorption and fluorescence measurements and is available at the Cryobench of the European Synchrotron Radiation Facility (ESRF), Grenoble, France. A detailed description of the apparatus, the setup of which does not involve a polarizer, has been reported (Royant et al., 2007; von Stetten et al., 2015).

In conjunction with this configuration, an open-flow helium cryostat (Helijet, Oxford Diffraction) was used, allowing the collection of data in a temperature range between 15 and $30 \mathrm{~K}$. This apparatus was modified to minimize ice formation during data collection and to achieve better temperature stability (McGeehan et al., 2009; van der Linden et al., 2013).

\subsection{X-ray diffraction of $\mathrm{NgbCO}$ at 15 and $40 \mathrm{~K}$ with and without illumination}

$\mathrm{X}$-ray data collections at low temperature were carried out on the ID14-2 beamline at ESRF at a wavelength of $0.933 \AA$ using an ADSC Q4 CCD detector. The temperature was set in a range between 15 and $40 \mathrm{~K}$ using the Helijet connected to a temperature controller, instead of the standard nitrogen cryostream. Cooled NgbCO crystals were mounted onto cryoloops and several diffraction data sets were collected from each sample at $40 \mathrm{~K}$ without illumination ('dark' state) and at $15 \mathrm{~K}$ under illumination ('light' state) by using an optical fibre microscope lamp, which was compatible with Helijet flow stability, whereas laser illumination geometry caused severe icing of the crystal and was thus avoided. With the aim of determining the structure of the photodissociation intermediate of $\mathrm{NgbCO}$, we collected data from several crystals in different experimental sessions by illuminating them before (30 min) and during data collection. All diffraction data sets were processed using MOSFLM (Leslie, 2006) and the structures were refined with REFMAC5 (Murshudov et al., 2011) from the CCP4 suite of programs (Winn et al., 2011). Refinement statistics are reported in Table 1.

Additional 'light-dark' recordings confirmed that full rebinding was achieved by collecting 'dark' data after a photolyzed data set had been acquired (data not shown).

\subsection{X-ray absorption near-edge spectroscopy (XANES) measurements of $\mathrm{NgbCO}$ in solution at 15 and $100 \mathrm{~K}$}

The previously reported Fe $K$-edge XANES spectra of NgbCO (Arcovito et al., 2008) were subjected to a different analysis that followed the MXAN procedure (Benfatto \& Longa, 2001), which is usually applied to normalized absolute spectra, in order to extract structural information on the $\mathrm{Ngb}$ photoproduct.

The $\mathrm{Ngb}^{*} \mathrm{CO}-\mathrm{NgbCO}$ XANES difference spectrum (Arcovito et al., 2008) was fitted and a structure of the metal site of the $\mathrm{Ngb} * \mathrm{CO}$ adduct was modelled using the following steps: (i) a reference XANES spectrum of $\mathrm{NgbCO}$ was calculated based on the NgbCO coordinates (PDB entry 1w92; Vallone, Nienhaus, Matthes et al., 2004) and using the real part of the Hedin-Lundqvist potential without including any damping factor, (ii) at each step the $M X A N$ package calculated the undamped $\mathrm{Ngb} * \mathrm{CO}$ theoretical spectrum, using the $\mathrm{Mb} * \mathrm{CO}$ coordinates (PDB entry 1abs; Schlichting et al., 1994), while varying the selected coordinate parameters shown in Table 3 and (iii) finally, the damping factors were convoluted 
Table 1

Crystallographic data-collection and refinement statistics for $\mathrm{NgbCO}$ and for ferric $\mathrm{Ngb}$ under 50 and 80 bar $\mathrm{O}_{2}$.

Values in parentheses are for the outer shell.

\begin{tabular}{|c|c|c|c|c|}
\hline & $\begin{array}{l}\mathrm{NgbCO} \text { ('dark') } \\
\text { at } 40 \mathrm{~K}\end{array}$ & $\begin{array}{l}\mathrm{Ngb} * \mathrm{CO} \text { ('light') } \\
\text { at } 15 \mathrm{~K}\end{array}$ & $\begin{array}{l}\text { Ferric under } 50 \text { bar } \\
\mathrm{O}_{2} \text { at } 100 \mathrm{~K}\end{array}$ & $\begin{array}{l}\text { Ferric under } 80 \text { bar } \\
\mathrm{O}_{2} \text { at } 100 \mathrm{~K}\end{array}$ \\
\hline PDB code & $6 \mathrm{i} 3 \mathrm{t}$ & $6 i 40$ & $5 \mathrm{mjc}$ & $5 \mathrm{mjd}$ \\
\hline \multicolumn{5}{|l|}{ Data collection } \\
\hline Beamline & ID14-2, ESRF & ID14-2, ESRF & BM14, ESRF & BM30-A, ESRF \\
\hline Wavelength $(\AA)$ & 0.933 & 0.933 & 0.8959 & 0.8559 \\
\hline Resolution range $(\AA ̊)$ & $\begin{array}{l}44.63-2.00 \\
\quad(2.10-2.00)\end{array}$ & $\begin{array}{l}44.63-1.90 \\
\quad(2.00-1.90)\end{array}$ & $\begin{array}{l}62.80-1.62 \\
\quad(1.67-1.62)\end{array}$ & $\begin{array}{l}63.09-1.70 \\
\quad(1.75-1.70)\end{array}$ \\
\hline Space group & $R 32$ & $R 32$ & $R 32$ & $R 32$ \\
\hline$a, b, c(\AA)$ & $88.06,88.06,110.16$ & $88.04,88.04,110.16$ & $87.35,87.35,112.65$ & $87.63,87.63,113.46$ \\
\hline$\alpha, \beta, \gamma\left({ }^{\circ}\right)$ & $90,90,120$ & $90,90,120$ & $90,90,120$ & $90,90,120$ \\
\hline Unique reflections & $11287(1614)$ & 12847 (1878) & 19661 (1071) & $16853(830)$ \\
\hline Multiplicity & $7.1(7.2)$ & $3.7(3.6)$ & $7.3(7.4)$ & $7.7(6.9)$ \\
\hline Completeness (\%) & $99.9(100.0)$ & $98.5(99.9)$ & $99.6(100.0)$ & $94.7(98.0)$ \\
\hline Mean $I / \sigma(I)$ & $27.2(7.5)$ & $16.9(3.0)$ & $21.4(4.3)$ & $20.3(3.8)$ \\
\hline$R_{\text {merge }} \dagger$ & $0.053(0.236)$ & $0.055(0.373)$ & $0.069(0.281)$ & $0.045(0.290)$ \\
\hline \multicolumn{5}{|l|}{ Refinement } \\
\hline Resolution range $(\AA)$ & $36.04-2.00$ & $36.03-1.90$ & $30.0-1.62$ & $20.0-1.70$ \\
\hline$R_{\text {work }} \ddagger$ & 0.17 & 0.17 & 0.168 & 0.179 \\
\hline$R_{\text {free }} \S$ & 0.22 & 0.21 & 0.207 & 0.242 \\
\hline \multicolumn{5}{|l|}{ No. of atoms } \\
\hline Protein & 1664 & 1715 & 1172 & 1172 \\
\hline Heme & 43 & 43 & 43 & 43 \\
\hline Sulfate & - & - & 5 & 5 \\
\hline Dioxane & - & - & 12 & - \\
\hline $\mathrm{CO}$ or $\mathrm{O}_{2}$ & 2 & 2 & 2 & 2 \\
\hline FMT & 9 & 9 & - & - \\
\hline ACT & 16 & 16 & - & - \\
\hline GOL & 12 & 12 & - & - \\
\hline Water & 99 & 101 & 144 & 128 \\
\hline \multicolumn{5}{|c|}{ Thermal $B$ factors $\left(\AA^{2}\right)$} \\
\hline Protein & 24.0 & 25.9 & 27.0 & 35.2 \\
\hline Heme & 22.5 & 23.65 & 16.5 & 20.1 \\
\hline Sulfate & - & - & 21.8 & 26.5 \\
\hline Dioxane & - & - & 30.0 & - \\
\hline FMT & 50.2 & 52.7 & - & - \\
\hline ACT & 43.8 & 47.6 & - & - \\
\hline GOL & 33.6 & 36.3 & - & - \\
\hline Ligand $\left(\mathrm{CO}\right.$ or $\left.\mathrm{O}_{2}\right)$ & 19.4 & 15.2 & 34.9 & 38.1 \\
\hline Water & 33.0 & 34.5 & 38.1 & 42.7 \\
\hline Overall & 24.8 & 26.7 & 27.4 & 34.8 \\
\hline \multicolumn{5}{|l|}{ R.m.s.d. from ideality } \\
\hline Bond lengths $(\AA)$ & 0.014 & 0.013 & 0.03 & 0.016 \\
\hline Bond angles $\left({ }^{\circ}\right)$ & 1.467 & 1.373 & 2.3 & 1.78 \\
\hline
\end{tabular}

$\dagger R_{\text {merge }}$ is defined as $\sum_{h k l} \sum_{i}\left|I_{i}(h k l)-\langle I(h k l)\rangle\right| / \sum_{h k l} \sum_{i} I_{i}(h k l)$, where $I_{\mathrm{i}}(h k l)$ is the $i$ th observation of reflection $h k l$ and $\left\langle I_{i}(h k l)\right\rangle$ is the weighted mean of all observations (after rejection of outliers). $\$ R_{\text {work }}$ is defined as $\sum_{h k l}|| F_{\text {obs }}|-| F_{\text {calc }}|| / \sum_{h k l}\left|F_{\text {obs }}\right|$ and indicates the accuracy of the model. $\& R_{\text {free }}$ is the cross-validation residual calculated using $5 \%$ of the data, which were randomly chosen and excluded from the refinement.

and directly fitted to the experimental $\mathrm{Ngb} * \mathrm{CO}-\mathrm{NgbCO}$ difference spectrum.

\subsection{X-ray diffraction (XRD) of ferric Ngb under 50 and} 80 bar $\mathrm{O}_{2}$ pressurization at $100 \mathrm{~K}$

Crystals under high dioxygen pressures (50 and 80 bar) were prepared using the soak-and-freeze technique as described previously (Lafumat et al., 2016). Diffraction data were collected during two consecutive runs on the BM14 and BM30A (FIP) beamlines at ESRF under cryogenic conditions $(100 \mathrm{~K})$ at wavelengths of 0.8859 and $0.8559 \AA$ for the 50 and 80 bar pressurized crystals, respectively. All data were processed with $X D S$ (Kabsch, 2010). The CCP4 program suite was used for subsequent scaling, merging and structure refinements. All crystals were isomorphous to the ferric Ngb crystals reported previously (Vallone, Nienhaus, Brunori et al., 2004). The models were subjected to iterative rounds of refinement and model building. Refinements were carried out with REFMAC5 (Murshudov et al., 2011) from $C C P 4$, followed by model adjustments and water additions with Coot (Emsley et al., 2010). The quality of the final models was analyzed using PROCHECK (Laskowski et al., 1993).

The atomic coordinates and structure factors have been deposited in the Protein Data Bank; the accession codes are reported in Table 1.

\section{Results and discussion}

3.1. Characterization of $\mathrm{NgbCO}$ photolytic intermediates

The complexity of $\mathrm{CO}$ rebinding in $\mathrm{Ngb}$ after photolysis has been described and attributed to $\mathrm{CO}$ migration from internal docking sites (Abbruzzetti et al., 2009; Nienhaus \& Nienhaus, 2004). Moreover, Nienhaus and coworkers investigated the ligand-binding reaction of NgbCO occurring after photolysis over a wide temperature range (3-353 K) using infrared and nanosecond time-resolved visible spectroscopy (Kriegl et al., 2002). They reported that photolysis at cryogenic temperatures populates a pentacoordinate 'deoxy' ferrous species $(\mathrm{Ngb} * \mathrm{CO})$ with very low geminate rebinding barriers; this state can be trapped below $40 \mathrm{~K}$, since at higher temperatures geminate rebinding becomes predominant. Therefore, we characterized single crystals of NgbCO by UVvisible optical microspectroscopy below $40 \mathrm{~K}$, and in parallel we determined the structure of $\mathrm{NgbCO}$ at $15 \mathrm{~K}$ under continuous visible-light illumination using the ESRF Cryobench (Royant et al., 2007; von Stetten et al., 2015). The heme environment of $\mathrm{NgbCO}$ was characterized by XANES measurements in solution at $15 \mathrm{~K}$ under long X-ray exposure.

3.1.1. UV-visible microspectrophotometry on $\mathrm{NgbCO}$ crystals at 15 and $30 \mathrm{~K}$. Ferric $\left(\mathrm{Fe}^{3+}\right)$, ferrous $\left(\mathrm{Fe}^{2+}\right)$ and ferrous $\mathrm{CO}$-bound $\left(\mathrm{Fe}^{2+}-\mathrm{CO}\right)$ crystals of $\mathrm{Ngb}$ were mounted 
onto cryo-loops and flash-cooled in liquid $\mathrm{N}_{2}(100 \mathrm{~K})$. The crystal orientation was optimized to maximize the signal from the heme metal centre while minimizing the baseline absorbance.

The absorption spectra of Ngb crystals in the ferric and ferrous (reduced with sodium dithionite) states at $15 \mathrm{~K}$ display the typical features of ferric Ngb and ferrous bis-histidyl hexacoordinate Ngb [Fig. 2(a)] as previously observed in solution (Brunori et al., 2005; Dewilde et al., 2001).

As far as absorption spectroscopy is concerned, the $\mathrm{Ngb} * \mathrm{CO}$ photolytic intermediate should correspond to a ferrous $\left(\mathrm{Fe}^{2+}\right)$ pentacoordinate species that differs from the ferric $\left(\mathrm{Fe}^{3+}\right)$ and ferrous $\left(\mathrm{Fe}^{2+}\right)$ hexacoordinate species, as shown in Fig. 2(a). Indeed, the spectrum obtained on exposing $\mathrm{NgbCO}$ crystals to continuous light at $15 \mathrm{~K}$ [Fig. 2(b), blue line] displays a single peak at $547 \mathrm{~nm}$ that corresponds to a ferrous pentacoordinate state, which has never so far been reported for wild-type $\mathrm{Ngb}$; this shows that the continuous halogen lamp of the microspectrophotometer is not only a probe but is sufficient to induce photolysis, yielding the formation of a ferrous pentacoordinate $\mathrm{Ngb}^{*} \mathrm{CO}$ species at $15 \mathrm{~K}$.

In order to demonstrate that the $\mathrm{CO}$ ligand is still trapped in the protein moiety of the $\mathrm{Ngb} * \mathrm{CO}$ intermediate species, we increased the temperature to $30 \mathrm{~K}$, where geminate rebinding becomes dominant. Accordingly, the resulting spectrum displayed two peaks ( $\sim 540$ and $\sim 560 \mathrm{~nm})$ : the spectroscopic signature of Ngb bound to CO [Fig. 2(b), green line] (Dewilde et al., 2001).

Finally, in order to confirm that the spectrum reported in Fig. 2(b) (blue line) unequivocally corresponds to that of $\mathrm{Ngb} * \mathrm{CO}$, we tested the reversibility of the whole process by proceeding with cycles of temperature increase from 15 to $30 \mathrm{~K}$ and decrease to $15 \mathrm{~K}$ (data not shown). The transition from the $\mathrm{Ngb} * \mathrm{CO}$ photolytic intermediate at $15 \mathrm{~K}$ to $\mathrm{CO}$ -

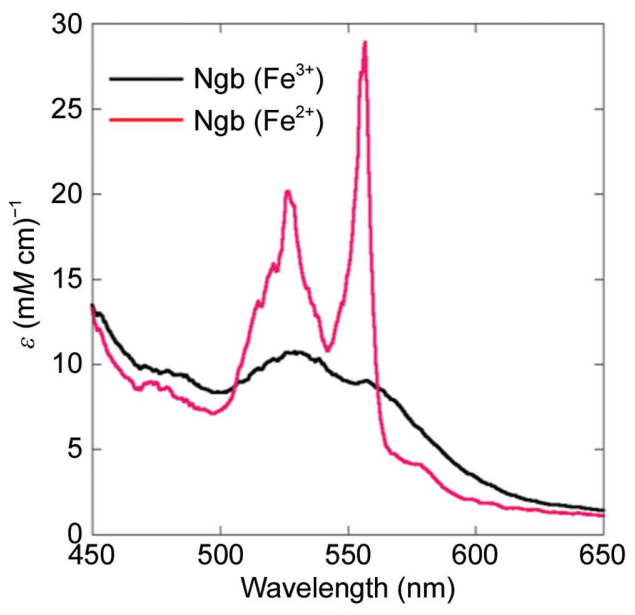

(a)

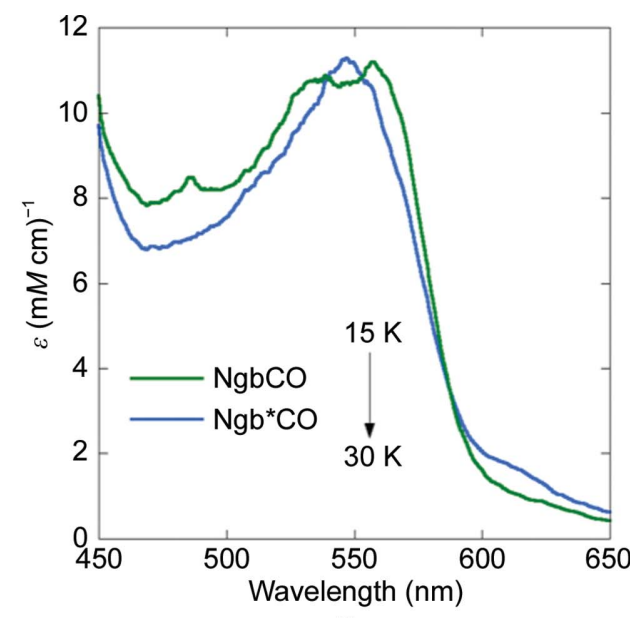

(b)
Figure 2

Absorption spectra of $\mathrm{Ngb}$ in crystallo at 15 and $30 \mathrm{~K}$. (a) In crystallo UV-visible spectra of ferric $\left(\mathrm{Fe}^{3+}\right)$ $\mathrm{Ngb}$ (black line) and hexacoordinate ferrous $\left(\mathrm{Fe}^{2+}\right) \mathrm{Ngb}$ (red line) were recorded at $15 \mathrm{~K}$. Hexacoordinate ferrous $\left(\mathrm{Fe}^{2+}\right) \mathrm{Ngb}$ crystals were obtained by soaking in mother liquor containing sodium dithionite, a reducing agent. (b) It is possible to trap the photolytic intermediate $\mathrm{Ngb} * \mathrm{CO}$ (cyan line) at $15 \mathrm{~K}$ under continuous illumination using the probing lamp of the microspectrophotometer. The $15-30 \mathrm{~K}$ temperature jump is associated with the geminate recombination of $\mathrm{CO}$ to the heme $\mathrm{Fe}$ atom (green line). bound $\mathrm{Ngb}$ at $30 \mathrm{~K}$ was shown to be reversible in the course of several cycles. At room temperature the spectrum of ferrous $\mathrm{Ngb}$ corresponds to that of a hexacoordinate state with the distal histidine occupying the sixth coordination position. Thus, by trapping the $\mathrm{Ngb}^{*} \mathrm{CO}$ pentacoordinate state of reduced $\mathrm{Ngb}$ in the crystal at $<30 \mathrm{~K}$ we demonstrated the feasibility of determining the three-dimensional structure of this photolytic intermediate.

3.1.2. XRD structures of $\mathrm{Ngb}$ at $40 \mathrm{~K}$ and of the $\mathrm{Ngb}^{*} \mathrm{CO}$ photolytic intermediate at $\mathbf{1 5} \mathrm{K}$. Crystal structures of $\mathrm{NgbCO}$ in the 'dark' state (no illumination) at $40 \mathrm{~K}$ and of $\mathrm{Ngb}^{*} \mathrm{CO}$ obtained under continuous illumination ('light' state) at $15 \mathrm{~K}$ were determined. Diffraction and refinement statistics are reported in Table 1.

The electron-density maps around the $\mathrm{Ngb}$ heme were contoured at $1.5 \sigma$ and are shown in Fig. 3. Upon refinement of the 'dark' state $\mathrm{NgbCO}$, the occupancy of heme-bound $\mathrm{CO}$ is estimated to be about $90 \%$. The partial CO occupancy is owing to the intrinsic instability of CO-bound $\mathrm{Ngb}$ crystals, which tend to dissolve upon full ligation. We therefore avoided prolonged $\mathrm{CO}$ soaking, with the drawback of not achieving full ligation. In this work, we only utilized crystals with at least $90 \%$ CO ligation, as assessed by its occupancy in the determined structures [Fig. 3(a)].

Under continuous illumination, the electron density for the heme group indicates the existence of a minor $\mathrm{Ngb}$ population in which $\mathrm{CO}$ is still bound to the heme $\left[10 \%\right.$ occupancy; $\mathrm{CO}_{\mathrm{B}}$ in Fig. 3(b)] and of a population in which $\mathrm{CO}$ is distinctly dissociated from the heme [ $40 \%$ occupancy; $\mathrm{CO}_{\mathrm{A}}$ in Fig. 3(b)]. Therefore, a high photolysis yield was achieved with only $10 \%$ geminate rebinding (or partial photolysis) under continuous illumination, consistent with IR (Kriegl et al., 2002) and visible spectroscopy at cryogenic temperature (reported above in Section 3.1.1). The minor fraction of CO-bound $\mathrm{Ngb}$ was either not detectable in the visible spectra or was caused by a temperature slightly higher than that achieved at the Cryobench, owing to the different sample geometry imposed by the diffraction data-collection setup.

The $40 \%$ occupancy of photodissociated $\mathrm{CO}$ is expected on the basis of Fourier transform infrared temperature-derivative spectroscopy data, indicating the presence of different subsites in the distal heme pocket (Lutz et al., 2009). We therefore conclude that this $40 \%$ occupies a lowmobility subsite and that the remaining photodissociated $\mathrm{CO}$ molecules $(50 \%$ of the total $\mathrm{CO}$ ) reside in nearby subsites or migrate to docking sites further away within the protein matrix, in both cases being characterized by high mobility and therefore not 
detectable by XRD. The presence of photolysed $\mathrm{CO}$ in the protein matrix, which was not visible in the $\mathrm{Ngb} * \mathrm{CO}$ structure, was inferred by the full recovery of bound $\mathrm{CO}$ in the 'dark' structures collected after illumination.

As shown in Fig. 3(b), the electron density is discontinuous between the iron and $\mathrm{CO}$, indicating bond rupture in crystallo under continuous illumination at $15 \mathrm{~K}$. In this $\mathrm{Ngb} * \mathrm{CO}$ pentacoordinate intermediate, the photodissociated $\mathrm{CO}$ lies on top of the heme pyrrole $\mathrm{C}$ ring, in a position similar, but not identical, to the 'primary docking site' observed in sperm whale Mb (swMb; Schlichting et al., 1994; Lim et al., 1995). In the $\mathrm{Ngb}$ 'primary docking site', the distance between the iron and the carbonyl $\mathrm{C}$ atom $\left(\mathrm{C}_{\mathrm{CO}}\right)$ is about $2.7 \AA$, which is larger than the $\mathrm{Fe}-\mathrm{C}_{\mathrm{CO}}$ distance $(1.9 \AA)$ measured for the coordination bond in $\mathrm{NgbCO}$ structures at both 40 and $100 \mathrm{~K}$ (PDB entry 1w92; Vallone, Nienhaus, Matthes et al., 2004). As a consequence of the photodissociation and of the subsequent $\mathrm{CO}$ displacement in the 'primary docking site', the distances between $\mathrm{CO}$ and residues lining the heme cavity changed, as reported in Table 2. Comparison with swMb*CO (Schlichting et al., 1994) shows that in $\mathrm{Mb}$ the $\mathrm{CO}$ molecule moves towards the distal His(E7)63, whereas in $\mathrm{Ngb}^{*} \mathrm{CO}$ it is displaced in the opposite direction within the distal pocket owing to the bulk of His(E7)64. Notably, His(E7)64 stays put in Ngb crystals, while the heme itself slides deeper to make room for the ligand upon binding, whereas in swMbCO His(E7)63 swings towards the bulk.

The set of side chains to which the photodissociated $\mathrm{CO}$ is closest includes Phe(B10)28, Phe(CD1)42, His(E7)64, $\operatorname{Val}(\mathrm{E} 11) 68$ and $\operatorname{Val}(\mathrm{G} 8) 109$. This is consistent with the effect

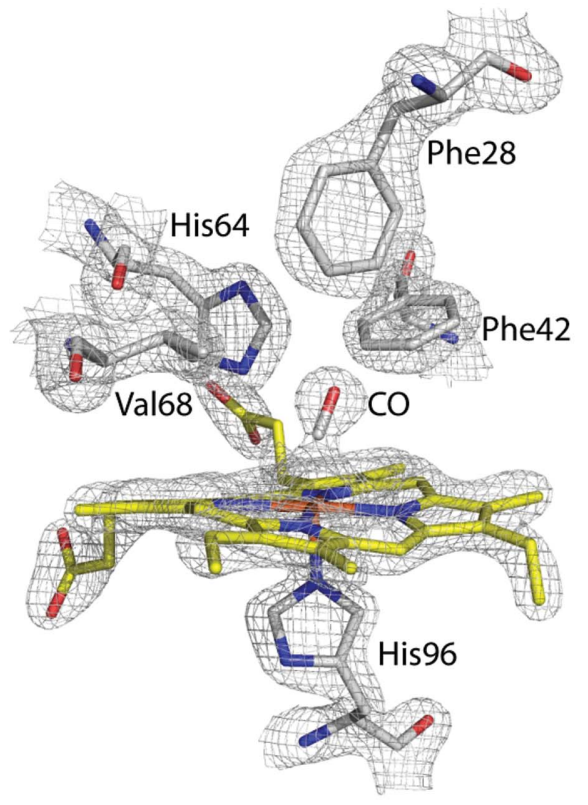

(a)

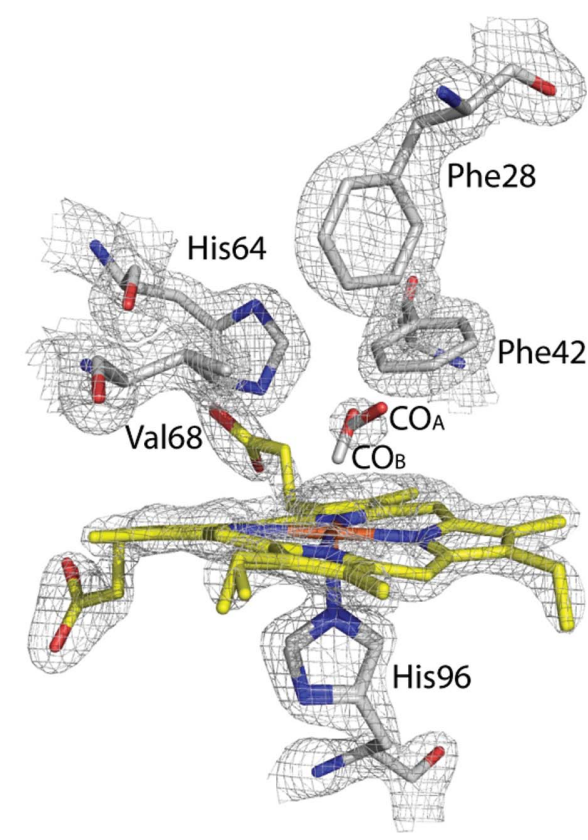

(b)
Figure 3

XRD electron-density maps of $\mathrm{NgbCO}$ at $40 \mathrm{~K}$ and of $\mathrm{Ngb} * \mathrm{CO}$ at $15 \mathrm{~K}$. (a) Close-up view of the heme pocket of $\mathrm{NgbCO}$ in the crystal structure determined at $40 \mathrm{~K}$ without illumination, showing a $2 F_{\mathrm{o}}-F_{\mathrm{c}}$ electron-density map contoured at $1.5 \sigma$. The occupancy of $\mathrm{CO}$ bound to the heme was estimated to be $90 \%$. (b) Close-up view of the heme pocket of $\mathrm{Ngb}^{*} \mathrm{CO}$ under illumination at $15 \mathrm{~K}$, showing the electron-density map contoured at $1.5 \sigma$. The occupancy of $\mathrm{CO}_{\mathrm{A}}$ is $40 \%$, whereas that of $\mathrm{CO}_{\mathrm{B}}$ was estimated to be about $10 \%$.
Table 2

XRD structures of NgbCO: distances between $\mathrm{CO}$ atoms and protein atoms.

In the second column we report the distances between $\mathrm{CO}$ and the atoms of its neighbouring residues measured for NgbCO (PDB entry 1w92; Vallone, Nienhaus, Matthes et al., 2004) at $100 \mathrm{~K}$ and in the third column we report those observed for the 'dark' form of $\mathrm{NgbCO}$ at $40 \mathrm{~K}$, while in the fourth column we report the distance between the photolyzed $\mathrm{CO}\left(\mathrm{CO}_{\mathrm{A}}\right)$ and its neighbouring protein atoms for the 'light' form at $15 \mathrm{~K}$. We only list distances of $<5.0 \AA$ for the atoms of the residues that are most involved in the ligandmigration process.

\begin{tabular}{llll}
\hline $\begin{array}{l}\text { Neighbouring } \\
\text { amino acid }\end{array}$ & $\begin{array}{l}\text { NgbCO, 100 K, } \\
\text { distance from CO } \\
\text { atoms }(\mathrm{C} / \mathrm{O})(\AA)\end{array}$ & $\begin{array}{l}\mathrm{NgbCO}, 40 \mathrm{~K}, \\
\text { distance from CO } \\
\text { atoms }(\mathrm{C} / \mathrm{O})(\AA)\end{array}$ & $\begin{array}{l}\mathrm{Ngb} * \mathrm{CO}, 15 \mathrm{~K}, \\
\text { distance from *CO } \\
\text { atoms }(\mathrm{C} / \mathrm{O})(\AA)\end{array}$ \\
\hline Val68 C C & $3.74 / 3.67$ & $3.67 / 3.72$ & $3.64 / 4.06$ \\
His64 C $^{\varepsilon 1}$ & $3.40 / 2.93$ & $3.80 / 3.06$ & $3.27 / 4.05$ \\
Phe28 C $^{\zeta}$ & $4.32 / 3.41$ & $4.08 / 3.20$ & $3.52 / 3.05$ \\
Phe42 C $^{\zeta}$ & $4.87 / 4.25$ & $4.93 / 4.03$ & $4.37 / 4.77$ \\
\hline
\end{tabular}

of an increase in the geminate rebinding fraction upon the mutation of Val68 to Phe, which would affect CO docking by steric hindrance (Astudillo et al., 2012). Notably, all residues that form the surface for $\mathrm{CO}$ docking in $\mathrm{Ngb}$, apart from His(E7)64, form a 'mechanical nucleus' that plays a key role in $\mathrm{Ngb}$ dynamics (Colloc'h, Carpentier et al., 2017).

3.1.3. Further analysis of the XANES spectra of $\mathrm{NgbCO}$ in solution under prolonged $\mathrm{X}$-ray irradiation at $15 \mathrm{~K}$. X-rayinduced photolysis has been characterized for swMbCO, for which the X-ray-induced and light-induced photoproducts at low temperatures are alike, suggesting that $\mathrm{CO}$ photolysis by prolonged X-ray irradiation is a common feature of CO-bound heme proteins and yields comparable intermediate species (Della Longa \& Arcovito, 2010; Milani et al., 2008).

In a previous study, XANES spectra of $\mathrm{NgbCO}$ were collected at $15 \mathrm{~K}$ under $\mathrm{X}$-ray exposure to investigate the $\mathrm{Ngb} * \mathrm{CO}$ photolytic intermediate (Arcovito et al., 2008). Starting from NgbCO in solution, a clear spectral evolution over time was observed when the beam spot was kept fixed, indicating that $\mathrm{Fe}-\mathrm{C}_{\mathrm{CO}}$ bond rupture was induced by $\mathrm{X}$-rays. Moreover, the observed spectral evolution and the existence of at least three isosbestic points (at 7117, 7128 and $7142 \mathrm{eV}$ ) in the XANES profile indicated that the whole process accounted for a two-state transition involving the ferrous hexacoordinate $\mathrm{NgbCO}$ species and the ferrous pentacoordinate $\mathrm{Ngb}^{*} \mathrm{CO}$ species. Since the whole process has been shown to be reversible, this experimental setup allowed the acquisition of the XANES 
Table 3

Comparison of structural parameters determined by XANES and XRD for NgbCO and MbCO.

Estimated standard uncertainties for XRD were calculated using DPIRfree (Cruickshank, 1999). Values in parentheses represent the statistical error of the last digits.

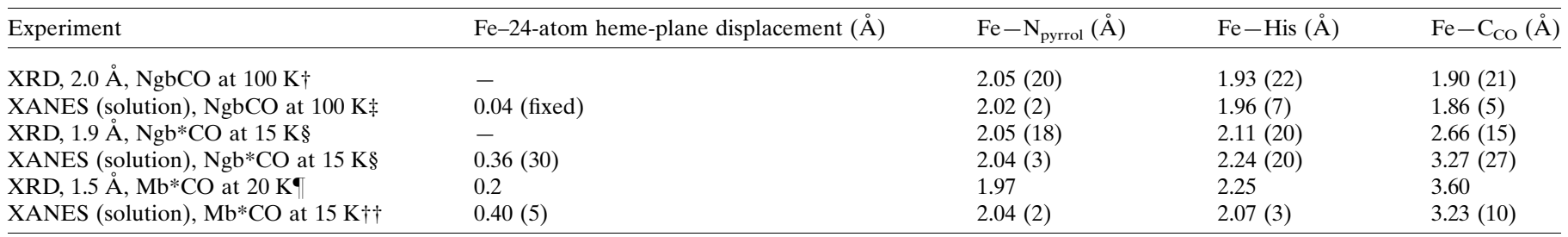

$\dagger$ Vallone, Nienhaus, Matthes et al. (2004). $\quad$ 末 Arcovito et al. (2010). § Present work. - Schlichting et al. (1994). †† Arcovito et al. (2005).

spectrum of a largely photolyzed $\mathrm{Ngb} * \mathrm{CO}$ intermediate species in solution after prolonged X-ray exposure at $15 \mathrm{~K}$. On the other hand, at $100 \mathrm{~K}$, where $\mathrm{CO}$ geminate rebinding is much faster than the XANES acquisition time, only the fully CO-bound $\mathrm{Ngb}$ spectrum was recovered ( $\mathrm{NgbCO}$ ). Here, a further analysis of the abovementioned data allows us to determine the $a b$ initio structure of the active site of the photolytic intermediate $\mathrm{Ngb} * \mathrm{CO}$ species to complement the structure obtained by XRD.

In previous work (Arcovito et al., 2008), only the fit of the absolute species $\mathrm{NgbCO}$ was obtained using the MXAN procedure, while no attempt to fit the structure of the photoinduced $\mathrm{Ngb} * \mathrm{CO}$ species in solution was performed, whereas in the new analysis presented here we applied the $M X A N$ package tool to the $\mathrm{Ngb} * \mathrm{CO}-\mathrm{NgbCO}$ difference spectrum. According to this procedure, it is possible to determine the structure of the X-ray-induced photolytic intermediate, assuming that the structure of the $\mathrm{NgbCO}$ bound species is known and that only a single $\mathrm{Ngb} * \mathrm{CO}$ species exists. Therefore, the $M X A N$ package fits the experimental data in the form of a difference spectrum, the interpretation of

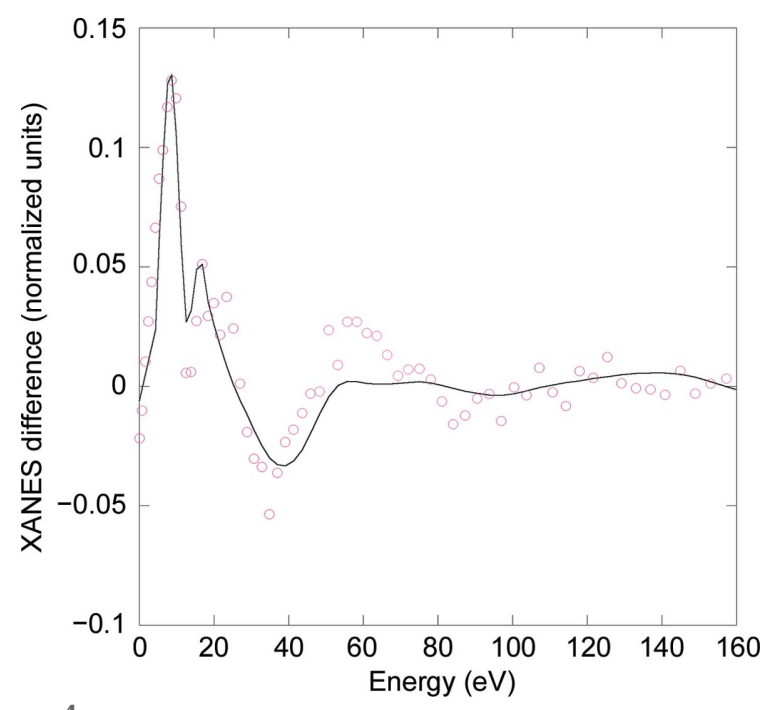

Figure 4

Further XANES analysis of the Ngb*CO-NgbCO difference spectrum at $15 \mathrm{~K}$. The experimental $\mathrm{Ngb} * \mathrm{CO}-\mathrm{NgbCO}$ difference spectrum (red open circles; Arcovito et al., 2008) was further analyzed and fitted (black solid line) using the $M X A N$ software. Fitting parameters are reported in Table 3. which would provide a description of the iron environment of the photoproduct in solution (Benfatto \& Longa, 2001; see Section 2). The resulting fit of the XANES difference profile is reported in Fig. 4 as a black continuous line, while the experimental difference spectrum is shown as red open circles. The fit is in overall agreement with the experimental data from 0 to $40 \mathrm{eV}$ and deviates slightly at increased energies (Fig. 4), as indicated by root-mean-square deviations (r.m.s.d.s) ranging from 0.012 to 0.029 normalized units, in comparison to an estimated noise of 0.01 normalized units. Theoretical systematic errors in the XANES fitting have been thoroughly discussed (D'Angelo et al., 2010; Arcovito et al., 2005) and it appears that they can be reduced by the analysis of a difference spectrum, which we performed in the new analysis reported here. Systematic errors are mostly owing to the poor approximation used for the phenomenological broadening function $\Gamma(E)$ adopted in the $M X A N$ method (Benfatto \& Longa, 2001), which mimics the electronic damping. However, systematic errors do not appreciably affect structural results, as has already been demonstrated for model systems such as Fe-porphyrin, Fe-heme and $\mathrm{Fe}(\mathrm{CN})_{6}$, confirming that XANES is more dependent on the geometry of the atomic cluster rather than its electronic structure (Arcovito et al., 2005; D'Angelo et al., 2008, 2010; Della Longa et al., 2001, 2003, 2009; Hayakawa et al., 2004; Lima et al., 2014; Chillemi et al., 2018). Notably, in our XANES analysis, the largest observed r.m.s.d. concerns the data obtained for energies ranging from 15 to $30 \mathrm{eV}$ and we therefore cannot exclude other sources of systematic error. However, calculated systematic errors do not affect our overall conclusions since we could unambiguously distinguish between different degrees of iron displacement with respect to the heme or to the $\mathrm{CO}$ photoproduct in the $\mathrm{Ngb} * \mathrm{CO}$ photolytic intermediate structure, as previously demonstrated for different light-induced sperm whale $\mathrm{Mb} * \mathrm{CO}$ photoproducts, to which the same fitting procedure was applied (Arcovito et al., 2005).

Fitting parameters from our new XANES analysis are reported in Table 3, together with those of the presently described XRD results and those derived from previously published XRD and XANES measurements on neuroglobin and myoglobin (Arcovito et al., 2010). Analysis of the $\mathrm{Ngb} * \mathrm{CO}-\mathrm{NgbCO}$ difference spectrum shows (i) an iron doming suggested by a heme-iron displacement of $0.36 \AA$ with respect to the 24-atom heme plane, similar to the displacement 
Table 4

Distances between the $\mathrm{O} 1$ and $\mathrm{O} 2$ atoms located in the storage site (Xe-III) and protein atoms.

\begin{tabular}{|c|c|c|}
\hline Pressure & 50 bar $\mathrm{O}_{2}$ & 80 bar $\mathrm{O}_{2}$ \\
\hline Neighbouring residue & Distances $(\mathrm{O} 1 / \mathrm{O} 2)(\AA)$ & Distances $(\mathrm{O} 1 / \mathrm{O} 2)(\AA)$ \\
\hline Ile72 $\mathrm{C}^{\gamma 1}$ & $4.51 / 4.27$ & $4.86 / 4.21$ \\
\hline $11 \mathrm{e} 72 \mathrm{C}^{\gamma 2}$ & $4.17 / 3.92$ & $4.40 / 3.94$ \\
\hline Ale $75 C^{\beta}$ & $-/ 4.04$ & $4.84 / 3.85$ \\
\hline Leu113 $C^{\delta 2}$ & $3.50 / 4.57$ & $3.84 / 4.53$ \\
\hline $\operatorname{Trp} 133 C^{\zeta 3}$ & $3.61 / 4.10$ & $3.66 / 4.21$ \\
\hline Tyr137 C ${ }^{\alpha}$ & $3.51 / 3.95$ & $3.46 / 4.10$ \\
\hline Tyr137 $C^{\delta 1}$ & $3.65 / 4.28$ & $3.98 / 4.33$ \\
\hline Tyr137 N & $3.65 / 4.04$ & $3.54 / 4.29$ \\
\hline Leu136 O & $4.61 / 4.37$ & $4.40 / 4.62$ \\
\hline Leu136 $C^{\delta 2}$ & $4.18 / 3.83$ & $3.97 / 4.14$ \\
\hline Leu136 $C^{\gamma}$ & $4.02 / 3.66$ & $3.59 / 3.81$ \\
\hline Val140 $C^{\gamma 2}$ & $4.58 / 3.70$ & $4.51 / 3.83$ \\
\hline
\end{tabular}

Only distances of $<5.0 \AA$ for $\mathrm{O}_{2}$ at 50 and 80 bar are listed.

observed in $\mathrm{Mb}^{*} \mathrm{CO}$, (ii) a distance of $2.04 \AA$ between the heme iron and $\mathrm{N}_{\text {pyrrol}}$, which is in good agreement with that measured for $\mathrm{Mb}$, (iii) an elongated distance between the heme and His(F8)96, yielding an $\mathrm{Fe}-\mathrm{N}^{\varepsilon}$ (His) distance of $2.24 \AA$, and (iv) a distance of $3.27 \AA$ between the heme iron and the $\mathrm{C}$ atom of the photolyzed $\mathrm{CO}$, which is similar to that reported for the $\mathrm{Fe}-{ }^{*} \mathrm{C}_{\mathrm{CO}}$ distance in $\mathrm{Mb} * \mathrm{CO}$ (from both XRD and XANES measurements; Arcovito et al., 2005; Schlichting et al., 1994), but somewhat different from the $\mathrm{Fe}-$ ${ }^{*} \mathrm{C}_{\mathrm{CO}}$ distance observed in $\mathrm{Ngb} * \mathrm{CO}(2.7 \AA)$ by XRD in this study. We ascribe this discrepancy to the $10 \% \mathrm{NgbCO}$ bound species present in the crystals upon visible-light illumination that may affect the estimate of the $\mathrm{Fe}-{ }^{*} \mathrm{C}_{\mathrm{CO}}$ distance, owing to the lower signal provided by the $\mathrm{CO}$ photolysed species. Therefore, performing an $M X A N$ analysis on an XANES difference spectrum allows a more accurate determination of the $\mathrm{Fe}-{ }^{*} \mathrm{C}_{\mathrm{CO}}$ distance to be obtained, since the fit isolates the contribution of the pentacoordinate $\mathrm{Ngb}^{*} \mathrm{CO}$ species.

Utilizing different illumination protocols or a customized light source compatible with the geometry of the helium cryostat could, in principle, improve the $\mathrm{CO}$ photolysis yield for XANES and bring it to the higher fraction observed in helium-temperature XRD. Photolysis owing to sole X-ray illumination, even at $15 \mathrm{~K}$, allows only the partial recovery of photolytic intermediates, in agreement with the low barriers to rebinding and the high geminate recombination observed for $\mathrm{Ngb}$ (Kriegl et al., 2002).

3.2. Characterization of a storage site for gaseous species in ferric Ngb: XRD structures of ferric Ngb under 50 and 80 bar $\mathrm{O}_{2}$ pressure at $100 \mathrm{~K}$

The localization of small gaseous ligands such as $\mathrm{CO}$ and $\mathrm{O}_{2}$ in the protein matrix is a nontrivial experimental task and is often inferred through indirect methods such as the use of xenon or halide anions as probes (Duff et al., 2004; Roeser et $a l ., 2007)$. In Ngb, the identification of potential small gaseous ligand-binding sites has been investigated using $\mathrm{Xe}, \mathrm{Kr}$ and $\mathrm{Ar}$ as probes (Abraini et al., 2014; Moschetti et al., 2009). These studies showed that the main noble-gas binding site with the highest occupancy is the Xe-III site located within the large heme cavity, while the occupancy in the Xe-IV site located between the Xe-III site and the heme was always lower (for example, at 40 bar Xe, $55 \%$ in Xe-IV compared with $85 \%$ in Xe-III; Colloc'h, Carpentier et al., 2017).

In this work, we used X-ray crystallography under a high pressure of $\mathrm{O}_{2}$ to directly detect the presence of docking sites for small diatomic gases.

In the past, accurate control of the gas pressure during diffraction experiments was only achievable during roomtemperature data collection, thus limiting the maximum pressure to about 50 bar owing to the limited resistance of quartz capillaries (Colloc'h et al., 2008). A recently developed technique consisting of cryocooling the crystal directly in the liquid phase of the pressurized gas under isobaric conditions allowed this limitation to be overcome and pressures of up to 100 bar to be reached, as long as both the gas and liquid phases coexist at the selected pressure (Lafumat et al., 2016). Therefore, diffraction data for ferric $\mathrm{Ngb}\left(\mathrm{Fe}^{3+}\right)$ were collected at 50 and 80 bar of pure molecular oxygen. This species is not competent for gaseous ligand binding, but is structurally identical within experimental error to the ferrous $\left(\mathrm{Fe}^{2+}\right)$ hexacoordinate species that can bind $\mathrm{O}_{2}$ or $\mathrm{CO}$ (Arcovito et al., 2008).

In spite of the limited equilibration time of the crystal in the gas phase $(5 \mathrm{~min})$ compared with the longer equilibration during $\mathrm{RT}$ experiments, one main $\mathrm{O}_{2}$-docking site is clearly observed at 50 and 80 bar $\mathrm{O}_{2}$ pressure, for which the occupancy increases from $50 \%$ at 50 bar to $85 \%$ at 80 bar [Figs. $5(c)$ and $5(d)$ ]. This cavity corresponds to the Xe-III site (Abraini et al., 2014; Colloc'h, Carpentier et al., 2017; Colloc'h, SacquinMora et al., 2017; Moschetti et al., 2009), which is devoid of electron density in all $\mathrm{Ngb}$ structures determined so far in the absence of pressurized gases [Figs. 5(a) and 5(b)]. Table 4 shows a list of the atoms lining the Xe-III niche and their distances from docked $\mathrm{O}_{2}$, within a radius of $5 \AA$. From this analysis, the hydrophobic nature of the Xe-III site surface is evident, since only two atoms out of 12 reported are polar. An analysis of the internal network of cavities in $\mathrm{Ngb}$, carried out using coarse-grained Brownian dynamic simulations, highpressure crystallography and mapping of noble-gas and nitrous oxide docking sites by XRD, led to the hypothesis that the Xe-III site acts as a storage site for small gaseous ligands (Abraini et al., 2014; Colloc'h, Carpentier et al., 2017; Colloc'h, Sacquin-Mora et al., 2017; Moschetti et al., 2009). This would be relevant for radical scavenging and, more generally, would support a catalytic role for Ngb. Indeed, as shown in Fig. 1, the Xe-III niche is located in the middle of the 'tunnel' connecting the bulk to the heme distal side and is sealed in the heme-slid NgbCO structure. We propose that the Xe-III site could host a diatomic molecule ready to react with an activated ligand bound to the heme, as observed for the reaction of $\mathrm{NgbO}_{2}$ with $\mathrm{NO}$ (Brunori et al., 2005). Therefore, the presence of $\mathrm{O}_{2}$ in the Xe-III cavity supports its role as a ligand-storage site in the context of a catalytic role for $\mathrm{Ngb}$. Our data show that none of the other cavities previously identified by $\mathrm{Xe}, \mathrm{Kr}$ and $\mathrm{Ar}$ docking, including the Xe-IV site close to the heme cavity 


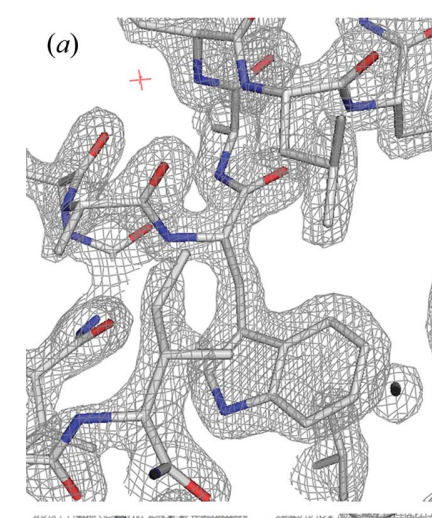

(c) $(4)$ (2)
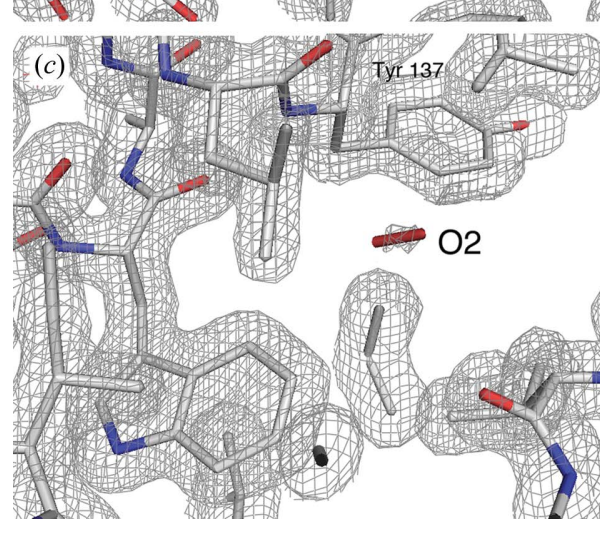
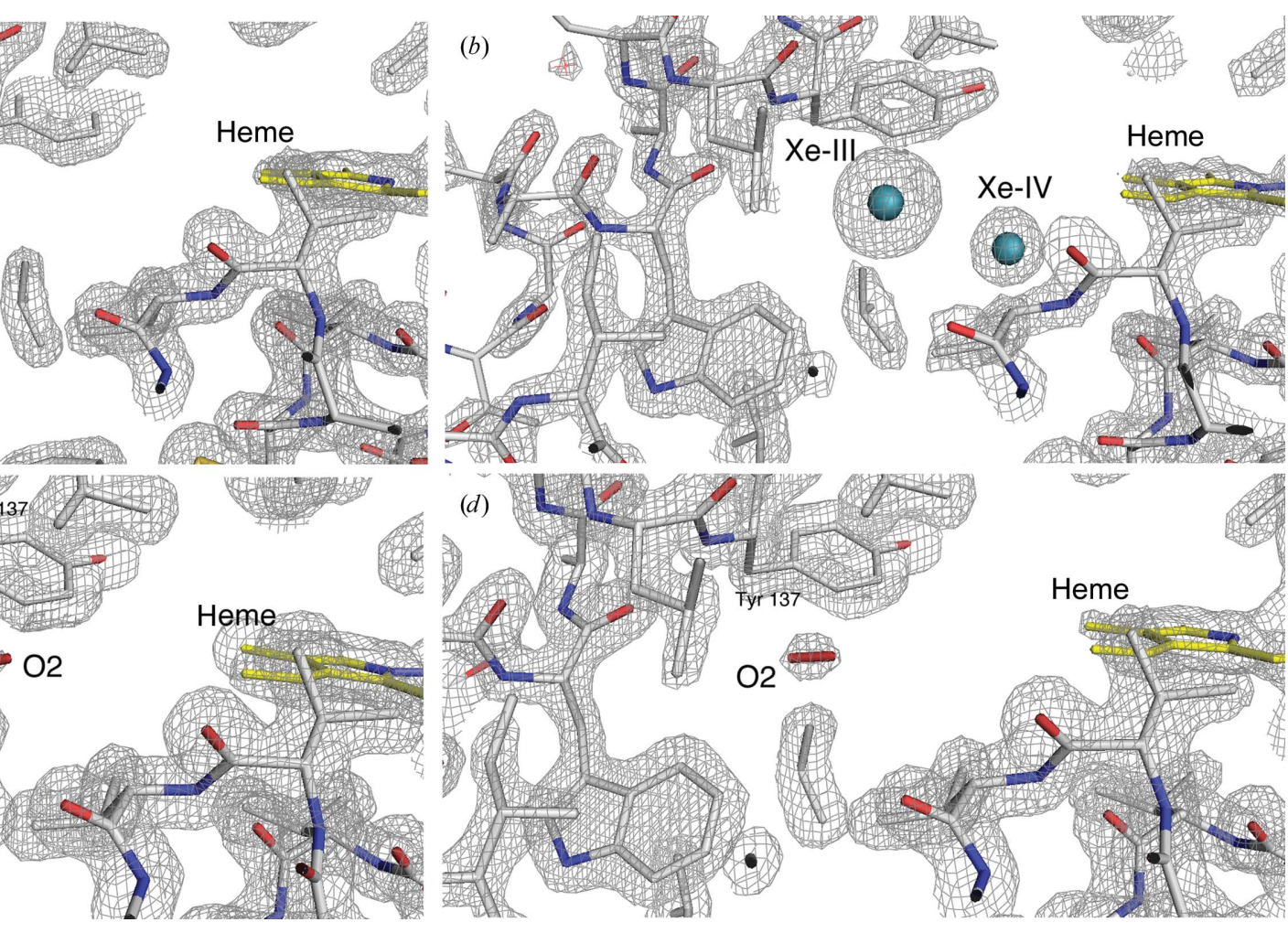

Figure 5

Oxygen-docking site in neuroglobin as determined by XRD at 50 and 80 bar $\mathrm{O}_{2}$. (a) The distal portion of the large internal cavity surrounding the heme as observed in the native ferric Ngb structure (PDB entry 1q1f; Vallone, Nienhaus, Brunori et al., 2004). (b) Ferric Ngb at 30 bar Xe showing the two internal sites (called Xe-III and Xe-IV) in the distal portion of the large cavity from PDB entry 3gk9 or 4o4t (Abraini et al., 2014; Moschetti et al., 2009). $(c, d)$ Ferric Ngb under 50 bar $(c)$ and 80 bar $(d) \mathrm{O}_{2}$ showing the dioxygen molecule (50\% occupancy at 50 bar versus $85 \%$ occupancy at 80 bar) only in the Xe-III site of $\mathrm{Ngb}$. Electron-density maps are contoured at $1.5 \sigma$.

[Fig. 5(b)], is occupied by $\mathrm{O}_{2}$ even when the pressure is raised to 80 bar.

\section{Conclusion}

Mapping docking sites inside a protein enables snapshots of events that govern its reactivity and dynamics to be obtained, and for neuroglobin it could provide relevant clues for pinpointing its mechanism of action and shedding light on its involvement in gas-sensing and radical scavenging. Therefore, we have used different biophysical approaches to investigate the structure of Ngb hosting diatomic gaseous molecules, such as $\mathrm{CO}$ and $\mathrm{O}_{2}$, which can dock in the large cavity surrounding the heme.

Notably, we combined ultralow-temperature X-ray diffraction and spectroscopy to determine the structure of the pentacoordinate $\mathrm{Ngb} * \mathrm{CO}$ photolytic intermediate, with the latter method yielding a more accurate description of its geometry than XRD.

Molecular-dynamics simulations have predicted the trajectories of gas diffusion in and out of proteins (Shadrina et al., 2016; Cohen et al., 2008; Anselmi et al., 2007). However, our experimental results, besides being relevant benchmarks for future simulations, directly provide a map of transient docking sites, which might represent structural snapshots of gas migration within neuroglobin.
By using complementary crystallographic approaches, i.e. ultralow-temperature and standard data collection at $100 \mathrm{~K}$, we have singled out the location of gaseous ligands immediately after dissociation or approaching the heme iron site for binding. No secondary docking sites for photodissociated $\mathrm{CO}$ were detected in the distal heme side of neuroglobin at low temperature, or at least not with an affinity and a reduced mobility compatible with trapping and detection by cryocrystallography. We do not exclude the potential design of mutations that would allow the detection of more elusive docking sites, as in the case of the myoglobin mutant Mb-YQR at $15 \mathrm{~K}$ (Brunori et al., 2000) or Mb L29W at a temperature above $180 \mathrm{~K}$ (Ostermann et al., 2000).

Moreover, the structure of ferric $\mathrm{Ngb}$ with internally docked $\mathrm{O}_{2}$ provides direct evidence for a ligand-storage location. These data, which show molecular oxygen hosted in the Xe-III site, confirm the predictive power of rare gases (Xe, $\mathrm{Kr}$ and $\mathrm{Ar}$ ) for identifying docking sites and internal paths within proteins, but highlight the importance of validating them using physiologically relevant ligands. Indeed, only one (Xe-III) of the two internal Xe sites identified in Ngb hosts molecular oxygen and it coincides with the region of the $\mathrm{Ngb}$ cavity network that binds noble gases with the highest occupancy. We therefore hypothesize that it constitutes a preferential path for ligand migration and/or a storage site for diatomic molecules. 


\section{Acknowledgements}

We acknowledge the European Synchrotron Radiation Facility for provision of synchrotron radiation facilities and we would like to thank Michel Pirocchi and Jean-Luc Ferrer for assistance in using beamline BM30-A, and Hassan Behlrali and Babu Manjasetty for assistance in using beamline BM14. IBS acknowledges integration into the Interdisciplinary Research Institute of Grenoble (IRIG, CEA). The authors declare no competing interests.

\section{Funding information}

This work received funding from the European Union's Horizon 2020 Innovative Training Network (ITN-ETN) program under the Marie Skłodowska-Curie X-probe project (Grant Agreement No. 637295 to BV).

\section{References}

Abbruzzetti, S., Faggiano, S., Bruno, S., Spyrakis, F., Mozzarelli, A., Dewilde, S., Moens, L. \& Viappiani, C. (2009). Proc. Natl Acad. Sci. USA, 106, 18984-18989.

Abraini, J. H., Marassio, G., David, H. N., Vallone, B., Prangé, T. \& Colloc'h, N. (2014). Anesthesiology, 121, 1018-1027.

Adachi, S., Park, S.-Y., Tame, J. R. H., Shiro, Y. \& Shibayama, N. (2003). Proc. Natl Acad. Sci. USA, 100, 7039-7044.

Amadei, A. \& Vallone, B. (1996). Proteins, 24, 35-50.

Anselmi, M., Brunori, M., Vallone, B. \& Di Nola, A. (2007). Biophys. J. 93, 434-441.

Arcovito, A., Ardiccioni, C., Cianci, M., D'Angelo, P., Vallone, B. \& Della Longa, S. (2010). J. Phys. Chem. B, 114, 13223-13231.

Arcovito, A., Benfatto, M., Cianci, M., Hasnain, S. S., Nienhaus, K., Nienhaus, G. U., Savino, C., Strange, R. W., Vallone, B. \& Della Longa, S. (2007). Proc. Natl Acad. Sci. USA, 104, 6211-6216.

Arcovito, A., Lamb, D. C., Nienhaus, G. U., Hazemann, J. L., Benfatto, M. \& Della Longa, S. (2005). Biophys. J. 88, 29542964.

Arcovito, A., Moschetti, T., D’Angelo, P., Mancini, G., Vallone, B., Brunori, M. \& Della Longa, S. (2008). Arch. Biochem. Biophys. 475, 7-13.

Ascenzi, P., Gustincich, S. \& Marino, M. (2014). IUBMB Life, 66, 268276.

Astudillo, L., Bernad, S., Derrien, V., Sebban, P. \& Miksovska, J. (2012). Biochemistry, 51, 9984-9994.

Avella, G., Ardiccioni, C., Scaglione, A., Moschetti, T., Rondinelli, C., Montemiglio, L. C., Savino, C., Giuffrè, A., Brunori, M. \& Vallone, B. (2014). Acta Cryst. D70, 1640-1648.

Barends, T. R. M., Foucar, L., Ardevol, A., Nass, K., Aquila, A., Botha, S., Doak, R. B., Falahati, K., Hartmann, E., Hilpert, M., Heinz, M., Hoffmann, M. C., Köfinger, J., Koglin, J. E., Kovacsova, G., Liang, M., Milathianaki, D., Lemke, H. T., Reinstein, J., Roome, C. M., Shoeman, R. L., Williams, G. J., Burghardt, I., Hummer, G., Boutet, S. \& Schlichting, I. (2015). Science, 350, 445-450.

Benfatto, M. \& Della Longa, S. (2001). J. Synchrotron Rad. 8, 10871094.

Bossa, C., Amadei, A., Daidone, I., Anselmi, M., Vallone, B., Brunori, M. \& Di Nola, A. (2005). Biophys. J. 89, 465-474.

Bourgeois, D., Vallone, B., Arcovito, A., Sciara, G., Schotte, F., Anfinrud, P. A. \& Brunori, M. (2006). Proc. Natl Acad. Sci. USA, 103, 4924-4929.

Brunori, M. (2000). Biophys. Chem. 86, 221-230.

Brunori, M. \& Gibson, Q. H. (2001). EMBO Rep. 2, 674-679.

Brunori, M., Giuffrè, A., Nienhaus, K., Nienhaus, G. U., Scandurra, F. M. \& Vallone, B. (2005). Proc. Natl Acad. Sci. USA, 102, 84838488 .
Brunori, M., Vallone, B., Cutruzzola, F., Travaglini-Allocatelli, C., Berendzen, J., Chu, K., Sweet, R. M. \& Schlichting, I. (2000). Proc. Natl Acad. Sci. USA, 97, 2058-2063.

Burmester, T. \& Hankeln, T. (2004). News Physiol. Sci. 19, 110-113.

Burmester, T., Weich, B., Reinhardt, S. \& Hankeln, T. (2000). Nature (London), 407, 520-523.

Chillemi, G., Anselmi, M., Sanna, N., Padrin, C., Balducci, L., Cammarata, M., Pace, E., Chergui, M. \& Benfatto, M. (2018). Struct. Dyn. 5, 054101.

Cohen, J., Olsen, K. W. \& Schulten, K. (2008). Methods Enzymol. 437, 439-457.

Colloc'h, N., Carpentier, P., Montemiglio, L. C., Vallone, B. \& Prangé, T. (2017). Biophys. J. 113, 2199-2206.

Colloc'h, N., Gabison, L., Monard, G., Altarsha, M., Chiadmi, M., Marassio, G., Sopkova-de Oliveira Santos, J., El Hajji, M., Castro, B., Abraini, J. \& Prangé, T. (2008). Biophys. J. 95, 2415-2422.

Colloc'h, N., Sacquin-Mora, S., Avella, G., Dhaussy, A. C., Prangé, T., Vallone, B. \& Girard, E. (2017). Sci. Rep. 7, 1858.

Cruickshank, D. W. J. (1999). Acta Cryst. D55, 583-601.

D’Angelo, P., Della Longa, S., Arcovito, A., Anselmi, M., Di Nola, A. \& Chillemi, G. (2010). J. Am. Chem. Soc. 132, 14901-14909.

D’Angelo, P., Lapi, A., Migliorati, V., Arcovito, A., Benfatto, M., Roscioni, O. M., Meyer-Klaucke, W. \& Della-Longa, S. (2008). Inorg. Chem. 47, 9905-9918.

Della Longa, S. \& Arcovito, A. (2010). Inorg. Chem. 49, 99589961.

Della Longa, S., Arcovito, A., Benfatto, M., Congiu-Castellano, A., Girasole, M., Hazemann, J. L. \& Lo Bosco, A. (2003). Biophys. J. 85, 549-558.

Della Longa, S., Arcovito, A., Girasole, M., Hazemann, J. L. \& Benfatto, M. (2001). Phys. Rev. Lett. 87, 155501.

Della Longa, S., Chen, L. X., Frank, P., Hayakawa, K., Hatada, K. \& Benfatto, M. (2009). Inorg. Chem. 48, 3934-3942.

Dewilde, S., Kiger, L., Burmester, T., Hankeln, T., Baudin-Creuza, V., Aerts, T., Marden, M. C., Caubergs, R. \& Moens, L. (2001). J. Biol. Chem. 276, 38949-38955.

Duff, A. P., Trambaiolo, D. M., Cohen, A. E., Ellis, P. J., Juda, G. A., Shepard, E. M., Langley, D. B., Dooley, D. M., Freeman, H. C. \& Guss, J. M. (2004). J. Mol. Biol. 344, 599-607.

Elber, R. \& Karplus, M. (1987). Science, 235, 318-321.

Emsley, P., Lohkamp, B., Scott, W. G. \& Cowtan, K. (2010). Acta Cryst. D66, 486-501.

Exertier, C., Milazzo, L., Freda, I., Montemiglio, L. C., Scaglione, A., Cerutti, G., Parisi, G., Anselmi, M., Smulevich, G., Savino, C. \& Vallone, B. (2019). Sci. Rep. 9, 5326.

Guimarães, B. G., Hamdane, D., Lechauve, C., Marden, M. C. \& Golinelli-Pimpaneau, B. (2014). Acta Cryst. D70, 1005-1014.

Hayakawa, K., Hatada, K., D'Angelo, P., Della Longa, S., Natoli, C. R. \& Benfatto, M. (2004). J. Am. Chem. Soc. 126, 15618-15623.

Jin, K., Mao, X., Xie, L., Khan, A. A. \& Greenberg, D. A. (2008). Neurosci. Lett. 4320, 135-137.

Kabsch, W. (2010). Acta Cryst. D66, 125-132.

Kriegl, J. M., Bhattacharyya, A. J., Nienhaus, K., Deng, P., Minkow, O. \& Nienhaus, G. U. (2002). Proc. Natl Acad. Sci. USA, 99, 79927997.

Lafumat, B., Mueller-Dieckmann, C., Leonard, G., Colloc'h, N., Prangé, T., Giraud, T., Dobias, F., Royant, A., van der Linden, P. \& Carpentier, P. (2016). J. Appl. Cryst. 49, 1478-1487.

Laskowski, R. A., MacArthur, M. W., Moss, D. S. \& Thornton, J. M. (1993). J. Appl. Cryst. 26, 283-291.

Leslie, A. G. W. (2006). Acta Cryst. D62, 48-57.

Lim, M., Jackson, T. A. \& Anfinrud, P. A. (1995). Science, 269, 962966.

Lim, M., Jackson, T. A. \& Anfinrud, P. A. (1997). Nat. Struct. Biol. 4, 209-214.

Lima, F. A., Penfold, T. J., van der Veen, R. M., Reinhard, M., Abela, R., Tavernelli, I., Rothlisberger, U., Benfatto, M., Milne, C. J. \& Chergui, M. (2014). Phys. Chem. Chem. Phys. 16, 1617-1631. 
Linden, P., Vitoux, H., Steinmann, R., Vallone, B. \& Ardiccioni, C. (2013). J. Phys. Conf. Ser. 425, 012015.

Lutz, S., Nienhaus, K., Nienhaus, G. U. \& Meuwly, M. (2009). J. Phys. Chem. B, 113, 15334-15343.

McGeehan, J., Ravelli, R. B. G., Murray, J. W., Owen, R. L., Cipriani, F., McSweeney, S., Weik, M. \& Garman, E. F. (2009). J. Synchrotron Rad. 16, 163-172.

Milani, M., Nardini, M., Pesce, A., Mastrangelo, E. \& Bolognesi, M. (2008). IUBMB Life, 60, 154-158.

Milani, M., Pesce, A., Ouellet, Y., Dewilde, S., Friedman, J., Ascenzi, P., Guertin, M. \& Bolognesi, M. (2004). J. Biol. Chem. 279, 2152021525.

Moschetti, T., Mueller, U., Schulze, J., Brunori, M. \& Vallone, B. (2009). Biophys. J. 97, 1700-1708.

Murshudov, G. N., Skubák, P., Lebedev, A. A., Pannu, N. S., Steiner, R. A., Nicholls, R. A., Winn, M. D., Long, F. \& Vagin, A. A. (2011). Acta Cryst. D67, 355-367.

Nienhaus, G. U., Mourant, J. R., Chu, K. \& Frauenfelder, H. (1994). Biochemistry, 33, 13413-13430.

Nienhaus, K. \& Nienhaus, G. U. (2004). Micron, 35, 67-69.

Ostermann, A., Waschipky, R., Parak, F. G. \& Nienhaus, G. U. (2000). Nature (London), 404, 205-208.

Pesce, A., De Sanctis, D., Nardini, M., Dewilde, S., Moens, L., Hankeln, T., Burmester, T., Ascenzi, P. \& Bolognesi, M. (2004). IUBMB Life, 56, 657-664.

Roeser, D., Schmidt, B., Preusser-Kunze, A. \& Rudolph, M. G. (2007). Acta Cryst. D63, 621-627.

Royant, A., Carpentier, P., Ohana, J., McGeehan, J., Paetzold, B., Noirclerc-Savoye, M., Vernède, X., Adam, V. \& Bourgeois, D. (2007). J. Appl. Cryst. 40, 1105-1112.

Sanctis, D. de, Dewilde, S., Pesce, A., Moens, L., Ascenzi, P., Hankeln, T., Burmester, T. \& Bolognesi, M. (2004). Biochem. Biophys. Res.
Commun. 316, 1217-1221.

Savino, C., Miele, A. E., Draghi, F., Johnson, K. A., Sciara, G., Brunori, M. \& Vallone, B. (2009). Biopolymers, 91, 1097-1107.

Schlichting, I., Berendzen, J., Phillips, G. N. Jr \& Sweet, R. M. (1994). Nature (London), 371, 808-812.

Schlichting, I. \& Chu, K. (2000). Curr. Opin. Struct. Biol. 10, 744-752.

Schmidt, M., Nienhaus, K., Pahl, R., Krasselt, A., Anderson, S., Parak, F., Nienhaus, G. U. \& Srajer, V. (2005). Proc. Natl Acad. Sci. USA, 102, 11704-11709.

Shadrina, M. S., English, A. M. \& Peslherbe, G. H. (2016). J. Chem. Theory Comput. 12, 2038-2046.

Stetten, D. von, Giraud, T., Carpentier, P., Sever, F., Terrien, M., Dobias, F., Juers, D. H., Flot, D., Mueller-Dieckmann, C., Leonard, G. A., de Sanctis, D. \& Royant, A. (2015). Acta Cryst. D71, 1526.

Tejero, J., Sparacino-Watkins, C. E., Ragireddy, V., Frizzell, S. \& Gladwin, M. T. (2015). Biochemistry, 54, 722-733.

Tilton, R. F. Jr, Kuntz, I. D. Jr \& Petsko, G. A. (1994). Biochemistry, 23, 2849-2857.

Tiso, M., Tejero, J., Basu, S., Azarov, I., Wang, X., Simplaceanu, V., Frizzell, S., Jayaraman, T., Geary, L., Shapiro, C., Ho, C., Shiva, S., Kim-Shapiro, D. B. \& Gladwin, M. T. (2011). J. Biol. Chem. 286, 18277-18289.

Vallone, B., Nienhaus, K., Brunori, M. \& Nienhaus, G. U. (2004). Proteins, 56, 85-92.

Vallone, B., Nienhaus, K., Matthes, A., Brunori, M. \& Nienhaus, G. U. (2004). Proc. Natl Acad. Sci. USA, 101, 17351-17356.

Winn, M. D., Ballard, C. C., Cowtan, K. D., Dodson, E. J., Emsley, P., Evans, P. R., Keegan, R. M., Krissinel, E. B., Leslie, A. G. W., McCoy, A., McNicholas, S. J., Murshudov, G. N., Pannu, N. S., Potterton, E. A., Powell, H. R., Read, R. J., Vagin, A. \& Wilson, K. S. (2011). Acta Cryst. D67, 235-242. 